\title{
Common Factors in Eurocurrency Rates: A Dynamic Analysis
}

\author{
Konstantinos Drakos \\ London Guildhall University
}

\begin{abstract}
The paper explores the issue of integration in the Eurocurrency market. In particular, by using information from the short end of the Eurodollar, Euromark and the Eurosterling term structures we focus on their multivariate correlation structure decomposing it into common (systemic) and idiosyncratic components. The empirical analysis employs the Johansen Multivariate Cointegration methodology and the Principal Components Analysis in order to test for the presence of any dynamic common factors among the selected Eurocurrency interest rates. The findings provide evidence in favour of an integrated market.

- JEL Classification: C10, E43, E44

- Key Words: Cointegration, Common Factors, Eurocurrency Market, Principal Component Analysis.
\end{abstract}

\section{Introduction}

The integration of international bond markets, or 'globalisation' has increased dramatically during the 1980's and 1990's (Caramaza et al., 1986; BlundellWignall and Browne, 1991; Frankel, 1992; Arshanapalli and Doukas, 1993, 1994; Goldstein and Mussa, 1993; Goodwin and Grennes, 1994; Bremnes et al., 1997; Fase and Vlaar, 1998). Integration of the bond markets is equivalent to interest rate convergence, defined as a tendency of interest rates across countries (different financial centres) to synchronise (Christiansen and Piggot, 1997).

Mundell (1968) provided a very intuitive economic rationale for interest rate

\footnotetext{
*Corresponding address: Dr. Kostas Drakos, Lecturer in Economics, Department of Economics, University of Essex Wivenhoe Park, Colchester, CO4 3SQ, Tel: +44-01206-872722, Email: kdrako@essex.ac.uk ()2002-Center for International Economics, Sejong Institution, All Rights Reserved.
} 
convergence based on first principles, where the degree of capital mobility would determine the degree of substitutability of international assets and ultimately would determine the extent of their comovement. In this context, given that there is sufficient capital mobility enabling meaningful substitutability among international assets, spreads will tend to narrow down and interest rates will move together.

Given the increasing deregulation (Gruijters, 1995), international capital mobility has accelerated international capital movements both in terms of speed and volume (Tesar and Warner, 1992). In that respect, Mundell's predictions are now more relevant than ever. However, although intuitive, Mundell's model cannot cope sufficiently with today's globalised markets. Therefore, one needs a different model to account for interest rate comovement. A model would serve for this purpose if it perceived international assets as being traded in a homogeneous market. Homogeneity here is defined as the situation where interest rates are determined not only by individual country's conditions but also by factors operating at the global level.

Two classes of models have this characteristic embedded in their construction. The first includes the Capital Asset Pricing Model (CAPM hereafter) (Sharpe, 1964) in its international form (Solnik, 1976), and the Consumption-based CAPM (Breeden, 1979). The second class includes Arbitrage Pricing Models (APT, hereafter) (Ross, 1976).

Modern theories dealing with the pricing of risk, identify asset risk as the 'additional' risk borne by the 'representative' investor when the particular asset is included in a well-diversified portfolio. Therefore, risk is expressed in terms of covariance (correlation) with a benchmark. For instance, in the international CAPM it is the covariance with the 'world' market portfolio that constitutes the so-called systemic risk, whereas in the Consumption based CAPM it is the covariance with the intertemporal marginal rate of substitution of consumption, and finally in the APT it is the covariance with a vector of fundamental risk factors. Although, the above models propose different ways of measuring risk, that is use different benchmarks, the important thing is their assertion that international assets are determined by a common set of international factors rather than country-specific factors alone. Empirical evidence for the presence of a set of common factors underlying the determination of interest rates has been provided by a number of researchers (Barro and Sala-i-Martin, 1990; Harvey, 1991; and Sutton, 1996).

The goals of the present paper are to explore to what extent international bond's interest rates have moved together, and furthermore, if comovement is present whether one can discern any pattern in it. To put more formally, the paper attempts 
to measure and interpret the common factors that describe the Eurocurrency market. The approach assumes that the correlation matrix of Eurocurrency interest rates can be decomposed into common or systemic components and idiosyncratic or non-systemic components. This decomposition is based on the underlying assumption that interest rates are linearly dependent to a set of common factors ${ }^{1}$ (APT, CAPM). A subset ${ }^{2}$ of Eurobond interest rates spanning different maturities from the short-end of the spectrum (1-month, 3-months, 6-months) denominated in Deutsche Mark, Pound Sterling, and US Dollar will be used.

The choice of the particular interest rates was based on three considerations. Firstly, it was essential that the sample included rates from different geographical and economic regions (financial centres). Secondly, it was also important to include different maturities in order to avoid maturity-specific inferences and also exploit the information embedded in the respective term structures. Thirdly, the Eurocurrency market is a non-domestic financial intermediary, so Eurocurrency assets are comparable in all aspects except currency of denomination. Further-more, they are less affected than on-shore rates by capital controls, tax consideraions and legal regulations, which could drive observed rates away from equilibrium levels. Finally, these rates do not depend on factors such as default risk, the calculation of yield etc.

The Eurobond market integration hypothesis will be investigated by employing two statistical tools: Firstly, the Johansen Multivariate Cointegration procedure (Johansen, 1988, 1991, 1995) will be used in order to uncover any common stochastic trends underlying the variables' dynamic paths. Secondly, a Principal Components Analysis (Hotelling, 1933) will be applied in order to test for the existence of any common factors affecting the rates' behaviour.

The paper will be organised as follows. Section 2 will describe the data used in the analysis. Section 3 will briefly provide the statistical background for the two methodologies. Section 4 will present the empirical results and finally Section 5 will conclude.

\section{Data Issues and Stationarity Tests}

The dataset consisted of end-of-month observations from the short-end of the

\footnotetext{
${ }^{1}$ For a similar application of the methodology see also Litterman and Scheinkman, (1989) and Knez et al. (1994).

${ }^{2}$ Utilizing information from the term structure comes at the expense of focusing on a lower number of countries. This trade-off is due to keeping the parameter space relatively moderate and thus save degrees of freedom.
} 
Table 1. Unit Root Tests ${ }^{\mathrm{a}}$

\begin{tabular}{|ccllll|}
\hline Level & ADF & PP & Difference & ADF & PP \\
\hline ED1 & -2.16 & -1.54 & ED1 & $-4.93^{*}$ & $-14.59^{*}$ \\
ED3 & -2.05 & -1.62 & ED3 & $-5.09^{*}$ & $-10.8^{*}$ \\
ED6 & -2.13 & -1.7 & ED6 & $-5.4^{*}$ & $-9.6^{*}$ \\
EM1 & -1.19 & -0.82 & EM1 & $-4.88^{*}$ & $-11.64^{*}$ \\
EM3 & -1.28 & -0.83 & EM3 & $-5.02^{*}$ & $-10.08^{*}$ \\
EM6 & -1.23 & -0.85 & EM6 & $-4.98^{*}$ & $-9.92^{*}$ \\
ES1 & -1.59 & -0.196 & ES1 & $-4.96^{*}$ & $-10.03^{*}$ \\
ES3 & -1.64 & -1.1 & ES3 & $-5.27^{*}$ & $-9.99^{*}$ \\
ES6 & -1.72 & -1.2 & ES6 & $-5.48^{*}$ & $-10.21^{*}$ \\
\hline
\end{tabular}

${ }^{a}$ ADF stands for the Augmented Dickey and Fuller $(1979,1981)$ 'pseudo' t-statistic with intercept. PP stands for the Phillips-Perron (1988) statistic with intercept. The asterisk denotes significance at the 5\% level. Critical value at the 5\% level is -2.89 . ED stands for Eurodollar, ES of Eurosterling and EM for Euromark, the number attached stands for the maturity of the interest rate.

nominal term structure of the Eurocurrency market for bonds with maturities of 1month, 3-months, and 6-months. The interest rates used were denominated in Deutsch Mark, Pound Sterling, and US Dollar. Sampling begins at November 1988 and ends November 2000 providing 144 data points available for the analysis $^{3}$. The Bank of International Settlements kindly supplied the data set.

Table 1 reports the unit root tests (Dickey and Fuller, 1979, 1981; Phillips and Perron, 1988) for the series.

As expected the null of non-stationarity was not rejected for the levels of all series implying that standard asymptotic theory cannot be applied. In contrast, the null of non-stationarity was comfortably rejected for the first differences of the series leading one to conclude that all of them were integrated of order one [I(1)].

\section{Econometric Methodology}

Since the primary goals of this paper are to explore the degree of interest rate convergence and to account for the variance among interest rates the Cointegration and Principal Components methods will be employed. The following two subsections will briefly review the statistical backgrounds for the two methods. The two statistical tools should not be perceived as competing, they are rather complementary. Both the Cointegration framework and the Principal Components

\footnotetext{
${ }^{3}$ Monthly rather than daily data were used to avoid problems with non-normality and excessive noise.
} 
Analysis focus on uncovering the common set of factors that can account for the realised in-sample correlation structure of the variables at hand. In that respect, they are set out to provide an answer to the same empirical question. Their complementarity ${ }^{4}$ arises from the fact that Cointegration focuses on the long run structure (and thus exploiting their stochastic trends), whereas Principal Components focuses on the short run structure ${ }^{5}$.

\section{A. The Johansen Procedure}

The Johansen procedure (Johansen, 1988, 1991, 1995) starts with the definition of an $n$-dimensional vector of non-stationary variables $X$, which potentially form a cointegrating set. The Vector Autoregressive (VAR) representation of the unrestricted system with Gaussian error $u$ is:

$$
X_{t}=A_{1} X_{t+1}+A_{2} X_{1+2}+\cdots+A_{k} X_{t+k}+u_{t}
$$

where

$$
u_{t} \sim N(0, \Sigma)
$$

and $X_{t}$ is $\left(\begin{array}{lll}n & \times & 1\end{array}\right)$ and each of the $A_{i}$ is an $\left(\begin{array}{lll}n & \times & n\end{array}\right)$ matrix of parameters.

Model (1) can be reformulated into a Vector Error Correction (VECM) form:

$$
\Delta X_{t}=\Gamma_{1} \Delta X_{t+1}+\Gamma_{2} \Delta X_{1+2}+\cdots+\Gamma_{k} \Delta X_{t+k}-\Pi X_{t-k}+u_{t}
$$

where

$$
\Gamma_{i}=-\left(I-A_{1}-\cdots-A_{i}\right) \quad i=1,2, \ldots, k-1
$$

and

$$
\Pi=-\left(I-A_{1}-\cdots-A_{i}\right)
$$

The rank of matrix $\Pi$ determines whether there are any significant cointegration vectors between the variables. Clearly if the rank of $\Pi$ is zero the matrix is null and (2) is just a VAR model in first differences. The other extreme case is when $\Pi$ has full column rank, which is equivalent to the stationarity of the vector process. The intermediate case of reduced column rank implies that there exist stationary linear combinations of the variables, corresponding to the cointegration

\footnotetext{
${ }^{4}$ Which basically provides the rationale for using both methods. I am grateful to an anonymous referee for pointing this out.

${ }^{5}$ The Principal Components analysis can be applied only to a set of stationary variables. Therefore it will be conducted on the interest rates' first differences. In that sense, any long run information will be lost.
} 
vectors. Furthermore, Johansen has developed a sequence of Likelihood Ratio (LR) tests to test for the number of the cointegration vectors (or equivalently the rank of $\Pi$ ) the so-called trace test (denoted by $\lambda_{t r}$ and the maximum eigenvalue test (denoted by $\lambda_{\max }$ ). Critical values obtained from Monte Carlo simulations of the limiting distribution are given in Johansen and Juselius (1990) and OsterwaldLenum (1992). The Johansen procedure is known to be sensitive to deviations from 'whiteness' for the residuals. In particular, autocorrelation has adverse effects on inference, therefore for that reason the lag length was chosen so as to guarantee that autocorrelation is absent.

\section{B. The Principal Components Analysis}

The Principal Components Analysis (PCA, hereafter) (Hotelling, 1933) ${ }^{6}$. Let ${ }^{7} z_{i t}$ denote the standardised $i$ th rate of interest at time $t$. If all interest rates observed move proportionately, then:

$$
z_{i t}=\alpha_{i} 1_{1 t}
$$

for all $i$ and $t$, with $a_{i l}$ a set of constants to be determined and $f_{t}$ the non-observable first principal component. In general, (3) will only hold approximately. Therefore, one seeks to determine those $\alpha_{i l}$ and $f_{i t}$, which will minimise the residual sum $S_{l}$, with:

$$
S_{1}=\sum_{t} \sum_{i}\left(z_{i t}-\alpha_{i 1} f_{1 t}\right)^{2}
$$

Because (4) is determined up to a constant factor usually the following normalisation is imposed:

$$
\sum_{i} f_{1 t}^{2}=1
$$

It can be shown that (4) attains its minimum when:

$$
f_{1 t}=\frac{1}{\lambda_{1}} \sum_{i} z_{i t} \alpha_{i l}
$$

where $\lambda_{1}$ denotes the largest eigenvalue of the ( $\left.p x p\right)$ matrix $\left(m_{i h}\right)$ with:

\footnotetext{
${ }^{6}$ For details see (Harman, 1968; Lawley and Maxwell, 1971).

${ }^{7}$ The paper follows very closely the exposition of (Fase, 1973; Fase, 1976; and Fase and Vlaar, 1998) who have established a comprehensive and easily communicated notation.
} 


$$
f_{1 t}=\frac{1}{\lambda_{1}} \sum_{i} z_{i t} \alpha_{i 1}
$$

and $i, h=1,2, \ldots, p$ while the $\alpha_{i 1}$ are derived from the elements of the corresponding eigenvector by multiplying with $\sqrt{\lambda_{1}}$. It may therefore, be shown that:

$$
\lambda_{1}=\sum_{i} a_{i 1}^{2}
$$

Expression (5) implies that $f_{1}$ is a linear function of the observed variables with coefficients proportional to the elements from the eigenvector corresponding to the largest eigenvalue $\lambda_{1}$. The second principal component may be taken in the same way from the resulting residuals. In general, the $k$ th principal component is obtained as:

$$
f_{k t}=\frac{1}{\lambda_{k}} \sum_{i} k_{i t} \alpha_{i k}
$$

It should also be noted that by construction each principal component is orthogonal to all others. In equation (8) $\lambda_{k}$ denotes the $k$ th eigenvalue of the matrix $\left(m_{i h}\right)$ ranked in descending order of magnitude. The factor loadings $\alpha_{i k}$ are computed from the corresponding eigenvector. Finally, again holds that:

$$
\lambda_{k}=\sum_{i} \alpha_{i k}^{2}
$$

In the case of standardised variables the matrix $\left(m_{i h}\right)$ turns into a correlation matrix. In such a case, the factor loadings correspond to the correlation coefficient between the $i$ th variable $z_{i}$ and the $k$ th principal component $f_{k}$. Also it should be noted that the sum of the eigenvalues equals the trace of the matrix $\left(m_{i h}\right)$, denoted by $\operatorname{tr}\left(m_{i h}\right)$, which equals $p$ if standardised variables are used. Each factor $f_{k}$ therefore accounts for a fraction of the total variation in $z_{i}$, given by:

The quantity $\varphi_{k}=\frac{\lambda_{k}}{\operatorname{tr}\left(m_{i h}\right)}$ is an unweighted average of the $R^{2}$ of the interest variables with $f_{k}$, and it is used as the coefficient of determination in regression analysis indicating the goodness of fit.

\section{Empirical Results}

First the Cointegration results will be presented followed by the PCA results. 
Table 2. Cointegration Results ${ }^{\mathrm{a}}$

\begin{tabular}{|c|c|c|c|c|c|}
\hline \multicolumn{6}{|c|}{ Panel A } \\
\hline \multirow[b]{2}{*}{ Null r } & \multirow[b]{2}{*}{ Alt/ve p-r } & \multicolumn{2}{|c|}{$\lambda_{\max }$} & \multicolumn{2}{|c|}{$\lambda_{t r}$} \\
\hline & & $\begin{array}{c}\text { Test } \\
\text { Statistic }\end{array}$ & $\begin{array}{c}\text { Critical } \\
\text { value }\end{array}$ & $\begin{array}{c}\text { Test } \\
\text { Statistic }\end{array}$ & $\begin{array}{l}\text { Critical } \\
\text { value }\end{array}$ \\
\hline 0 & 9 & $79.3^{*}$ & 57.12 & $356.58^{*}$ & 192.89 \\
\hline 1 & 8 & $64.37^{*}$ & 51.42 & $277.28^{*}$ & 156 \\
\hline 2 & 7 & $56.05^{*}$ & 45.28 & $212.91^{*}$ & 124.24 \\
\hline 3 & 6 & $54.66^{*}$ & 39.37 & $156.86^{*}$ & 94.15 \\
\hline 4 & 5 & $38.41^{*}$ & 33.46 & $102.2^{*}$ & 68.52 \\
\hline 5 & 4 & $37.72^{*}$ & 27.07 & $63.8^{*}$ & 47.21 \\
\hline 6 & 3 & 14.49 & 18.06 & 26.07 & 29.68 \\
\hline 7 & 2 & 8.01 & 12.07 & 11.59 & 15.41 \\
\hline 8 & 1 & 3.58 & 2.69 & 3.58 & 3.76 \\
\hline \multicolumn{6}{|c|}{ Panel B } \\
\hline \multicolumn{6}{|c|}{ Multivariate Diagnostics } \\
\hline \multicolumn{3}{|c|}{ Test Statistic ${ }^{b}$} & \multicolumn{3}{|c|}{ P-value } \\
\hline \multicolumn{3}{|c|}{ L-B(35) } & \multicolumn{3}{|c|}{0.21} \\
\hline \multicolumn{3}{|c|}{$\operatorname{LM}(1)$} & \multicolumn{3}{|c|}{0.55} \\
\hline \multicolumn{3}{|c|}{$\mathrm{LM}(4)$} & \multicolumn{3}{|c|}{0.61} \\
\hline \multicolumn{6}{|c|}{ Panel C } \\
\hline \multicolumn{3}{|c|}{ Univariate Diagnostics } & \multicolumn{3}{|c|}{ Long Run Exclusion / Weak Exogeneity Tests ${ }^{\mathrm{c}}$} \\
\hline Equation & $\mathrm{ARCH}(3)$ & $\mathrm{R}^{2}$ & Equation & Exclusion & Weak Ex/ty \\
\hline ED1 & 1.56 & 0.68 & ED1 & $49.27^{*}$ & $58.10^{*}$ \\
\hline ED3 & 1.57 & 0.48 & ED3 & $45.91^{*}$ & $38.31^{*}$ \\
\hline ED6 & 8.17 & 0.4 & ED6 & $38.73^{*}$ & $29.46^{*}$ \\
\hline EM1 & 1.08 & 0.48 & EM1 & $40.1^{*}$ & $38.1^{*}$ \\
\hline EM3 & 1.76 & 0.36 & EM3 & $39.52^{*}$ & $26.94^{*}$ \\
\hline EM6 & 6.99 & 0.31 & EM6 & $34.93^{*}$ & $20.05^{*}$ \\
\hline ES1 & 0.9 & 0.43 & ES1 & $44.97^{*}$ & $21.08^{*}$ \\
\hline ES3 & 3.46 & 0.39 & ES3 & $44.63^{*}$ & $20.13^{*}$ \\
\hline ES6 & 6.35 & 0.33 & ES6 & $42.36^{*}$ & $15.38^{*}$ \\
\hline
\end{tabular}

${ }^{a}$ The asterisk denotes significance at the $5 \%$ level. The estimation included an unrestricted intercept. For the maximal eigenvalue test the null is for at most $r$ cointegration vectors, against the alternative of $r+$ $l$ cointegration vectors. For the trace test the null is at most $r$ cointegration vectors, with more than $r$ vectors under the alternative.

${ }^{b} \mathrm{~L}-\mathrm{B}$ stands for the Ljung-Box autocorrelation statistic. LM stands for the Lagrange Multiplier autocorrelation statistic.

${ }^{c}$ Both the Long Run exclusion and Weak Exogeneity tests are distributed as chi-square with 6 degrees of freedom. The critical value at the $5 \%$ significance level is 12.59 .

\section{A. Cointegration Results}

The finding that all series were I(1) naturally leads to the use of the Johansen 
procedure. The Johansen procedure is known to be sensitive to deviations from 'whiteness' for the residuals. In particular, autocorrelation has adverse effects on inference. For that reason the lag length was chosen by the means of the Schwartz Criterion (Schwartz, 1978) so as to guarantee that autocorrelation is absent.

Table 2 summarises the results for the cointegration rank of the system. The Schwartz criterion led to the selection of a lag order of 3.

Applying a battery of multivariate autocorrelation tests (Panel B, Table 2) and univariate heteroscedasticity tests (Panel C, Table 2), residual 'whiteness' was established. The null hypothesis of 'white' (homoscedastic, non-autocorrelated) residuals was not rejected.

As far as the cointegration rank of the system is concerned, both the maximum eigenvalue and trace statistics (Panel A of Table 2) indicate that at the 5\% significance level there exist six (6) cointegration vectors. Furthermore, a LongRun exclusion test was applied for each of the rates in order to test whether it should be included in the system (Panel $\mathrm{C}$ of Table 2). The null was rejected for each case implying that all interest rates were taking part in the cointegration space

Figure 1. Beta 1 (first cointegration vector).


The difference between the upper and the lower graphs is that beta* $Z k(t)$ pictures the actual disequilibrium as a function of all short-run dynamics. Whereas beta* $R k(t)$ is corrected for the short-run effects, and pictures the clean disequilibrium. It is the series in the lower graph that is actually tested for stationarity and thus determines $r$ in the maximum likelihood procedure (for more details see Jansen and Juselius, 1995). 
Figure 2. Beta 2(second cointegration vector).

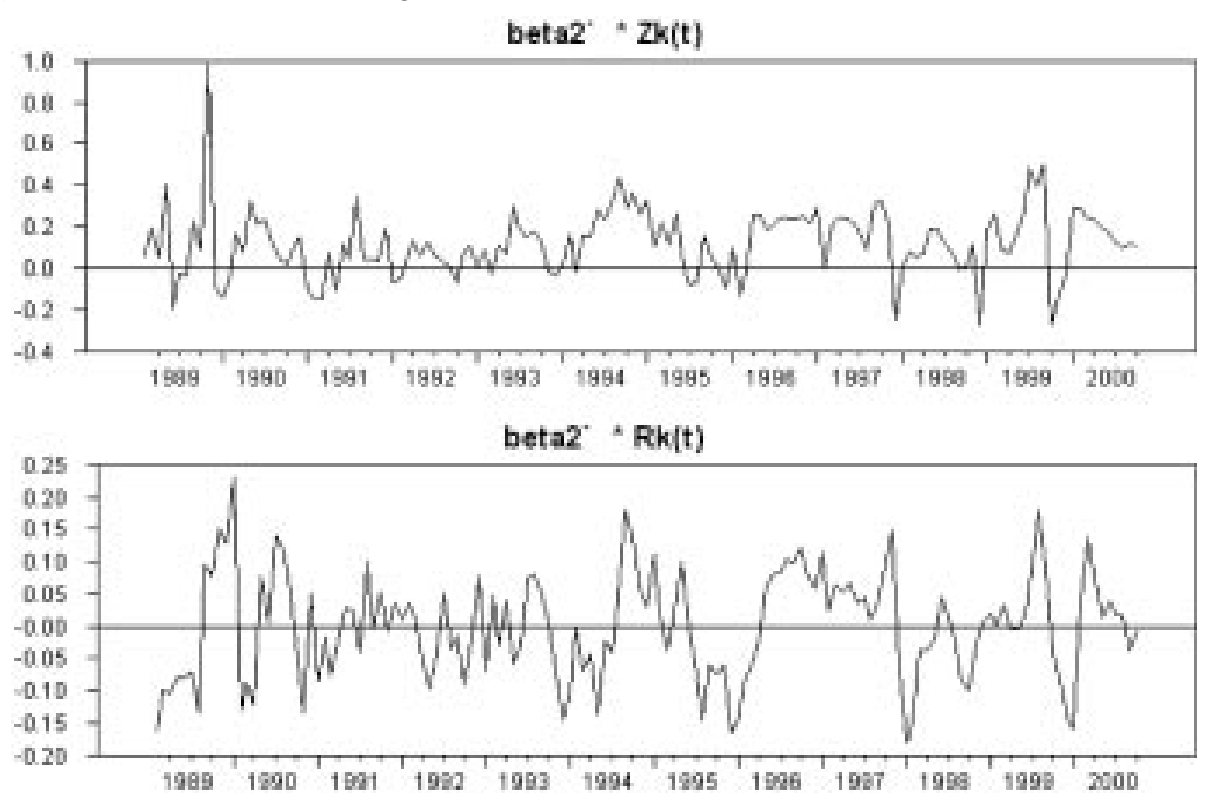

Figure 3. Beta 3(third cointegration vector).
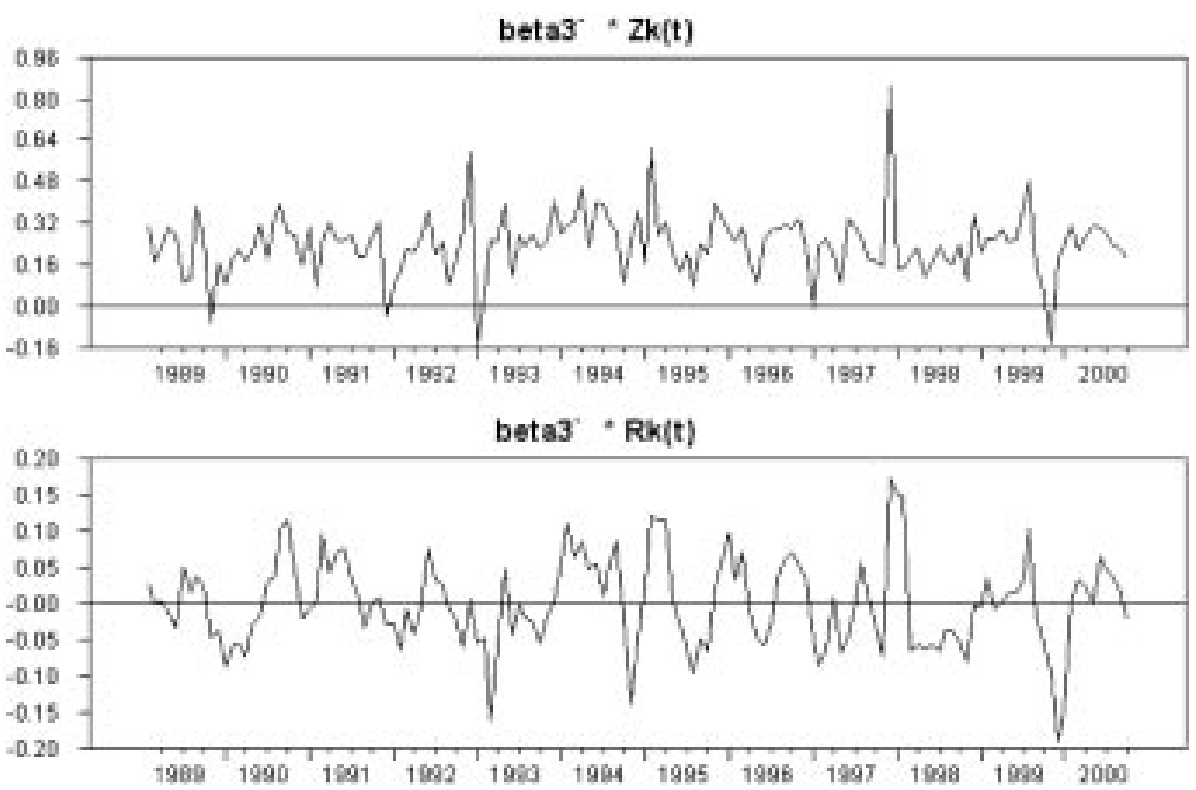

spanned.

The Figures section at the end of the paper presents the time series paths of the cointegration vectors (Figures 1 to 6) as well as the residuals' (Figures 7 to 15). Given the presence of six cointegration vectors between the nine interest rates 
Figure 4. Beta 4 (fourth cointegration vector).
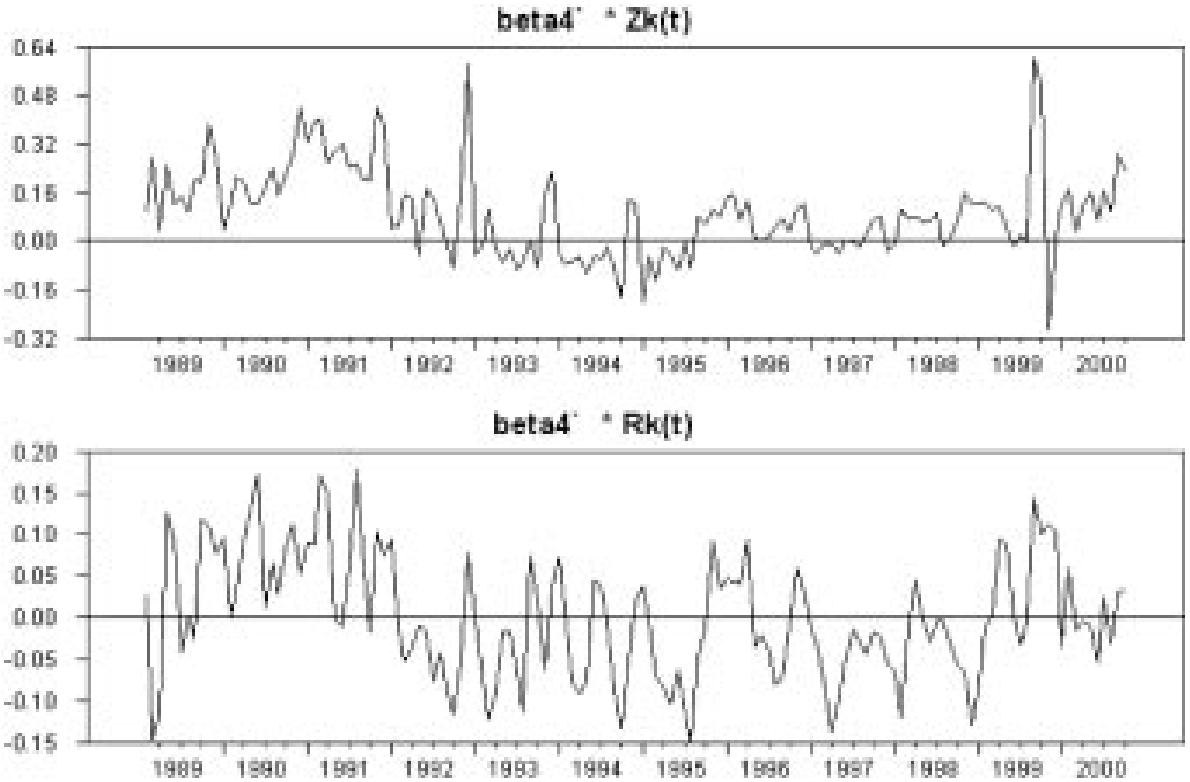

Figure 5. Beta 5 (fifth cointegration vector).
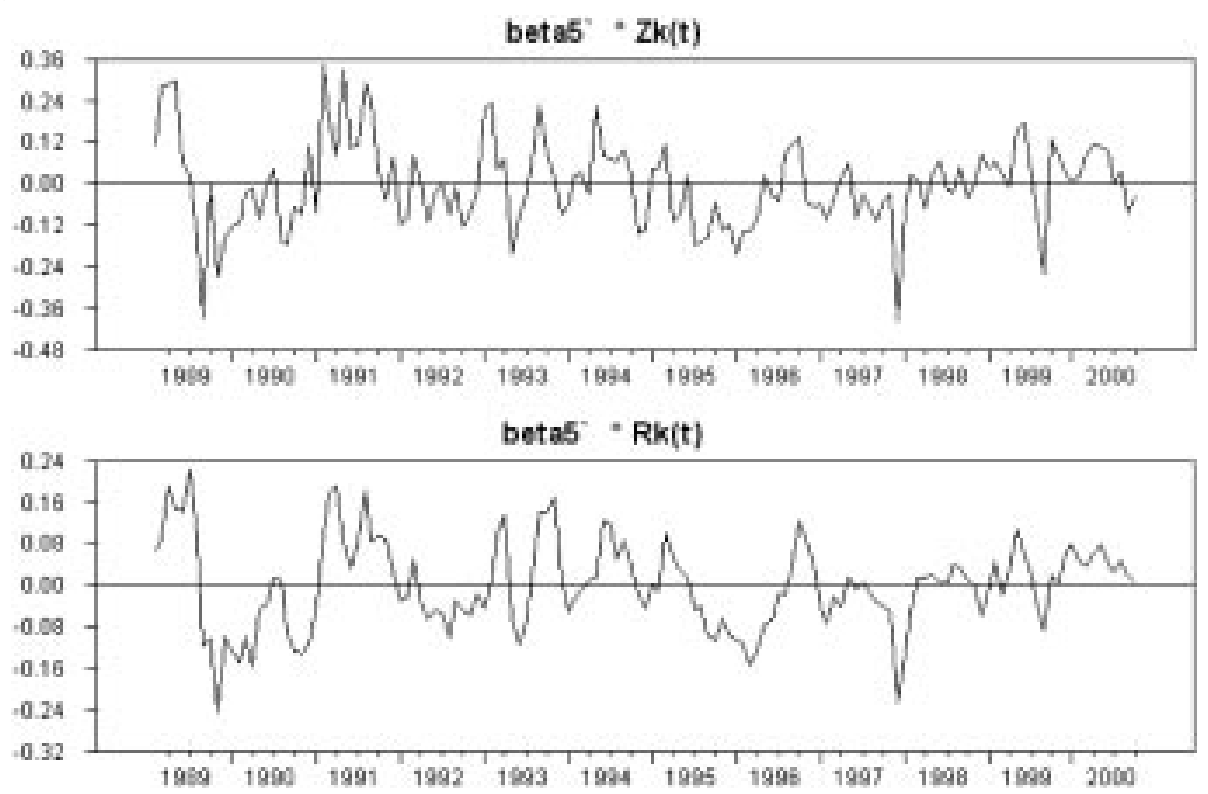

one may conclude that there exist three common stochastic trends between them. Therefore in conclusion, on the basis of this evidence, one cannot reject the hypothesis that long run dynamic linkages between Eurocurrency rates across the short-end of the nominal term structure do exist. This finding implies that 
Figure 6. Beta 6 (sixth cointegration vector).

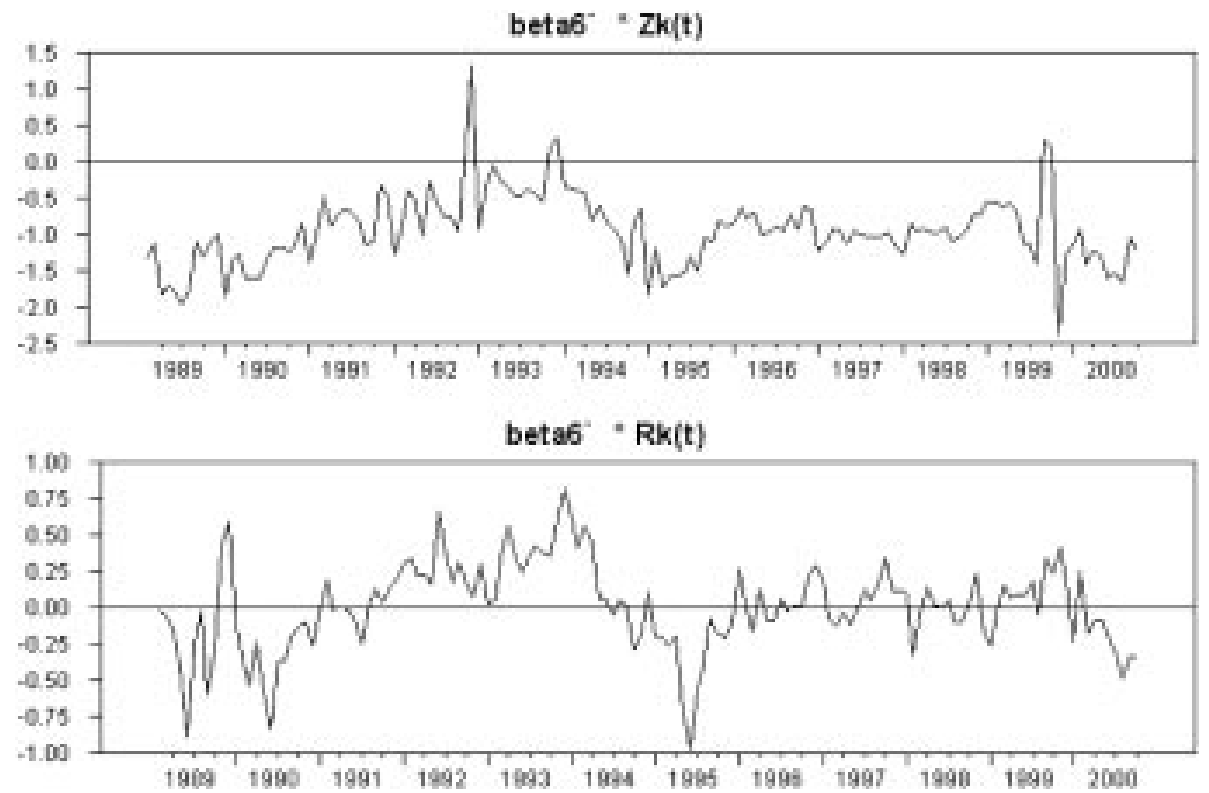

Figure 7. Residual series (ED1 equation).
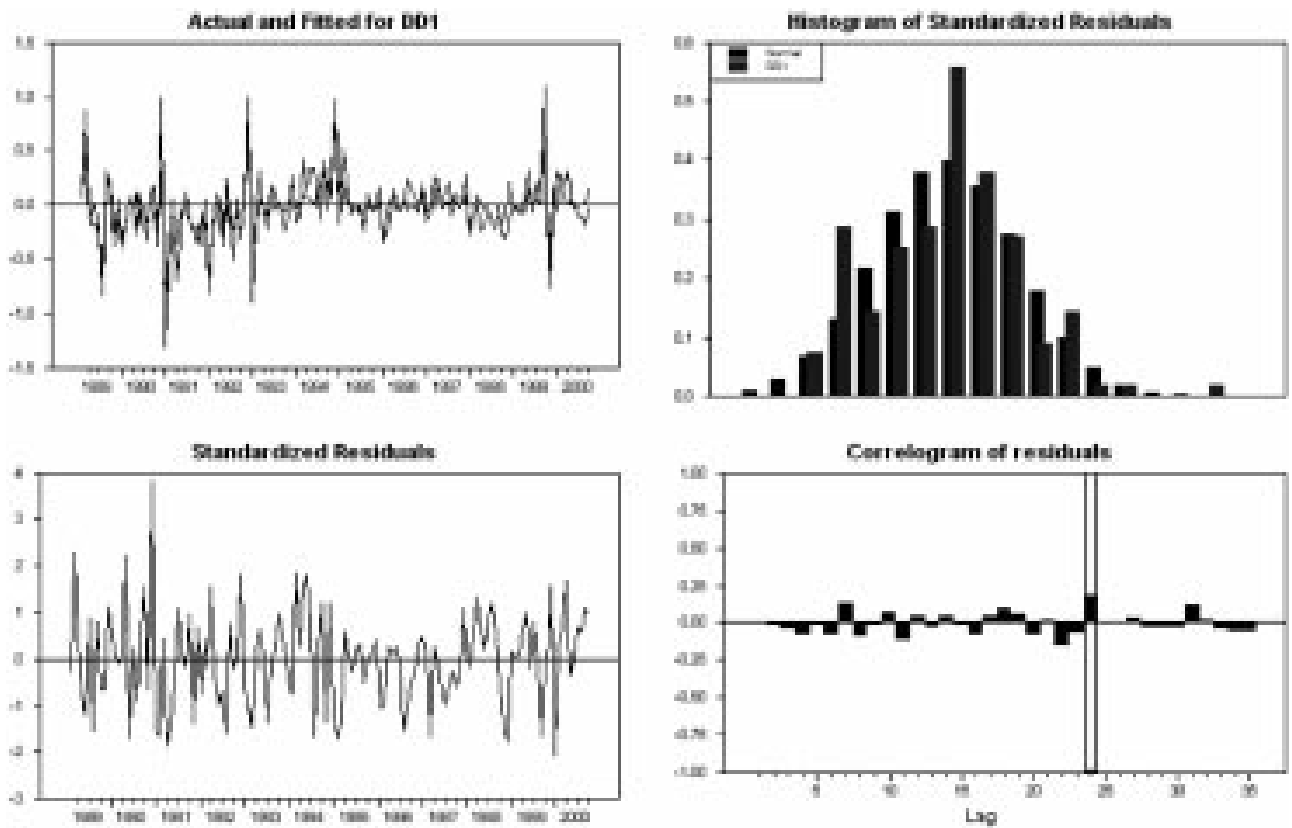

EDi stands for Eurodollar of maturity $i$, ESi stands for Eurosterling of maturity $i$, and finally EMi stands for Euromark of maturity $i$. 
Figure 8. Residual series (ES1 equation).
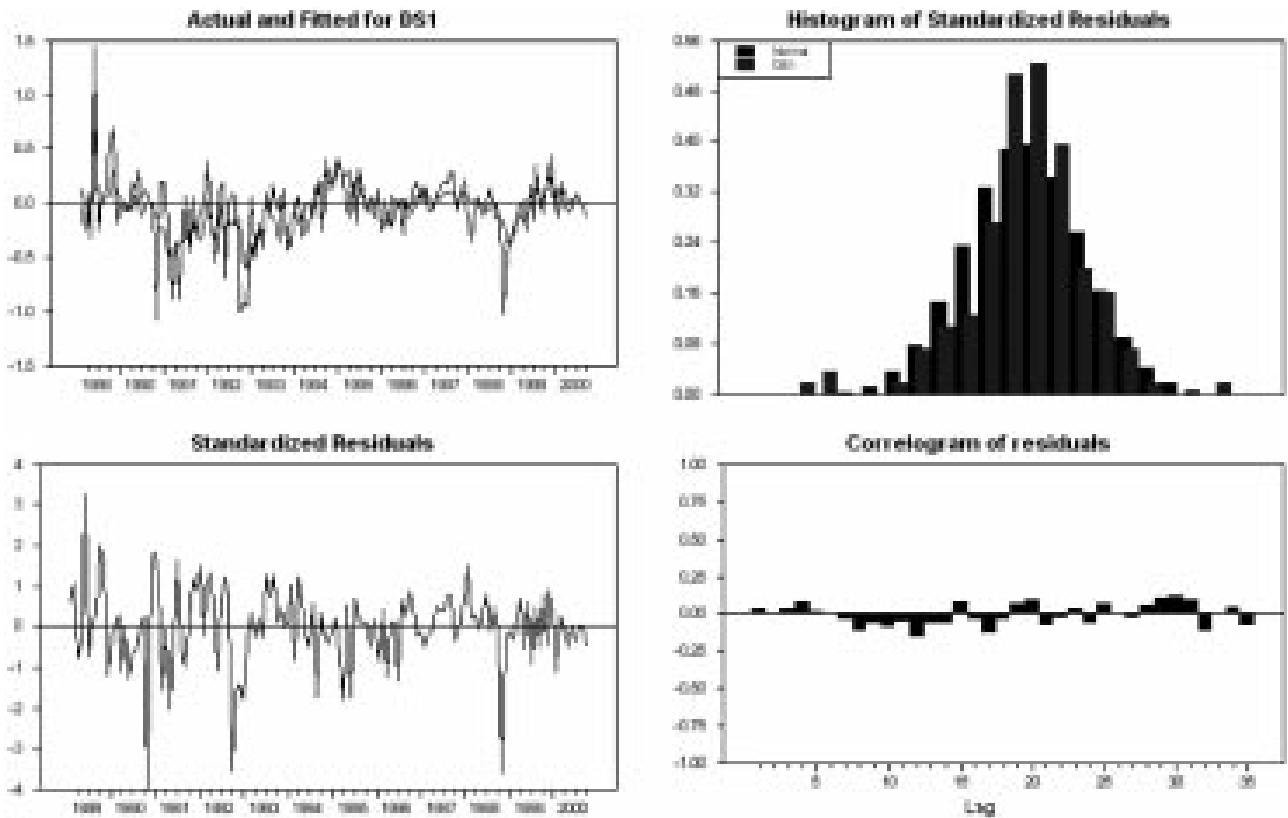

Figure 9. Residual series (EM1 equation).
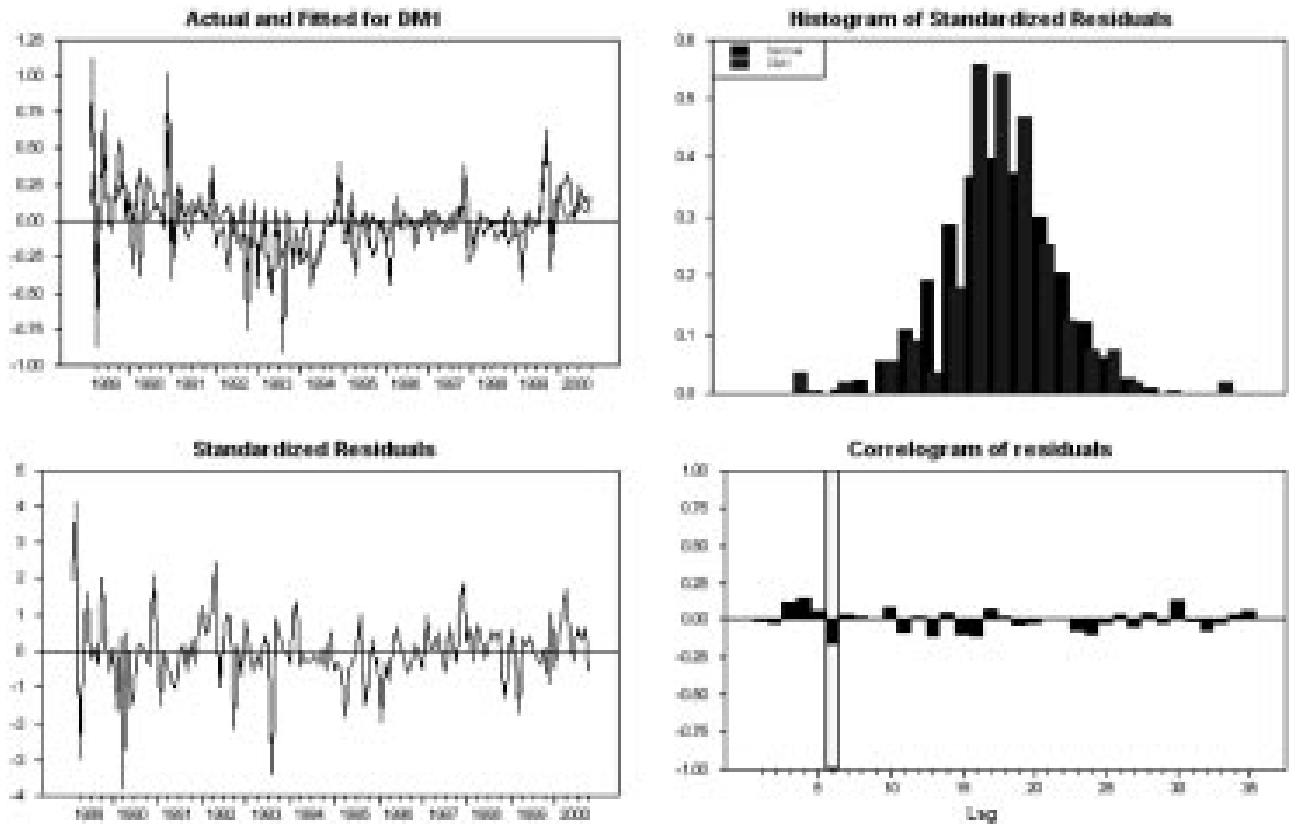
Figure 10. Residual series (ED3 equation).
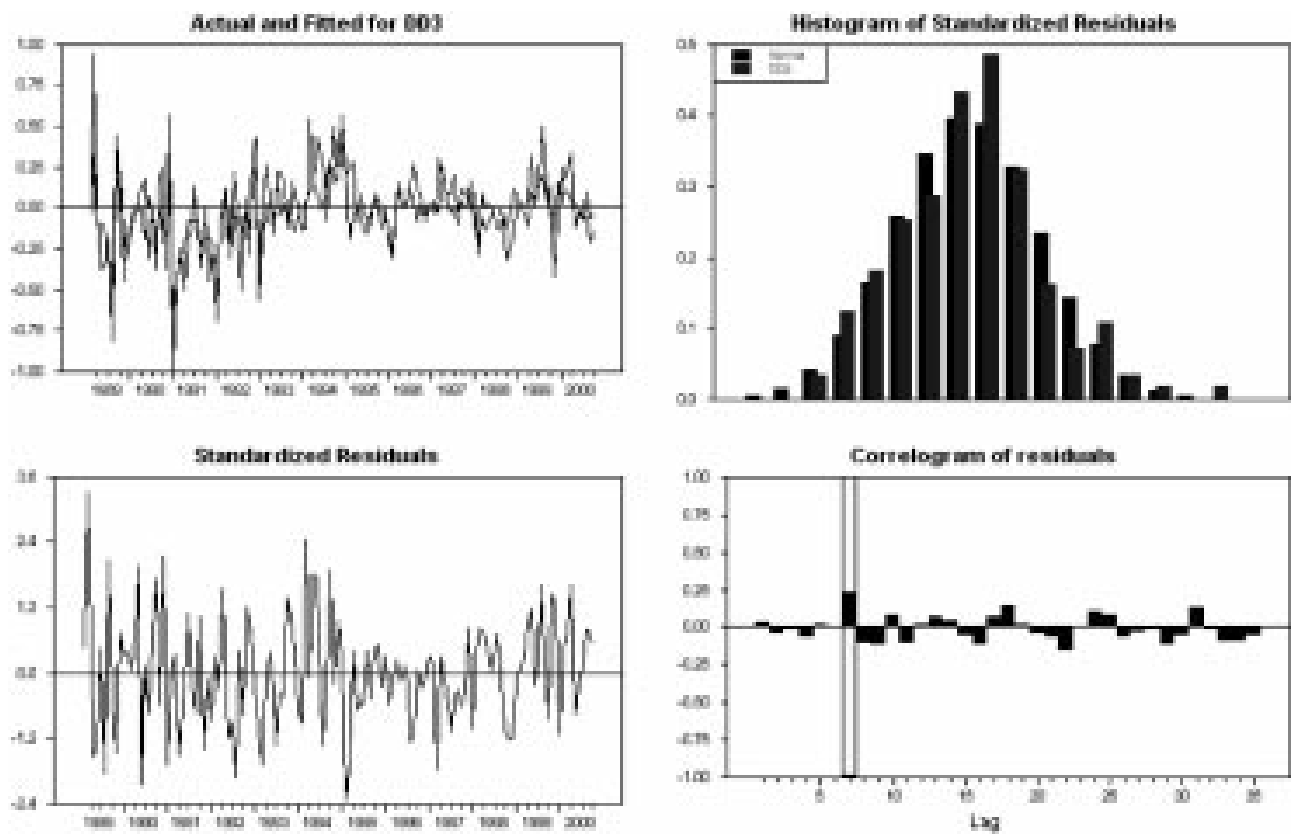

Figure 11. Residual series (ES3 equation).

Figure 12. Residual series (ED3 equation).
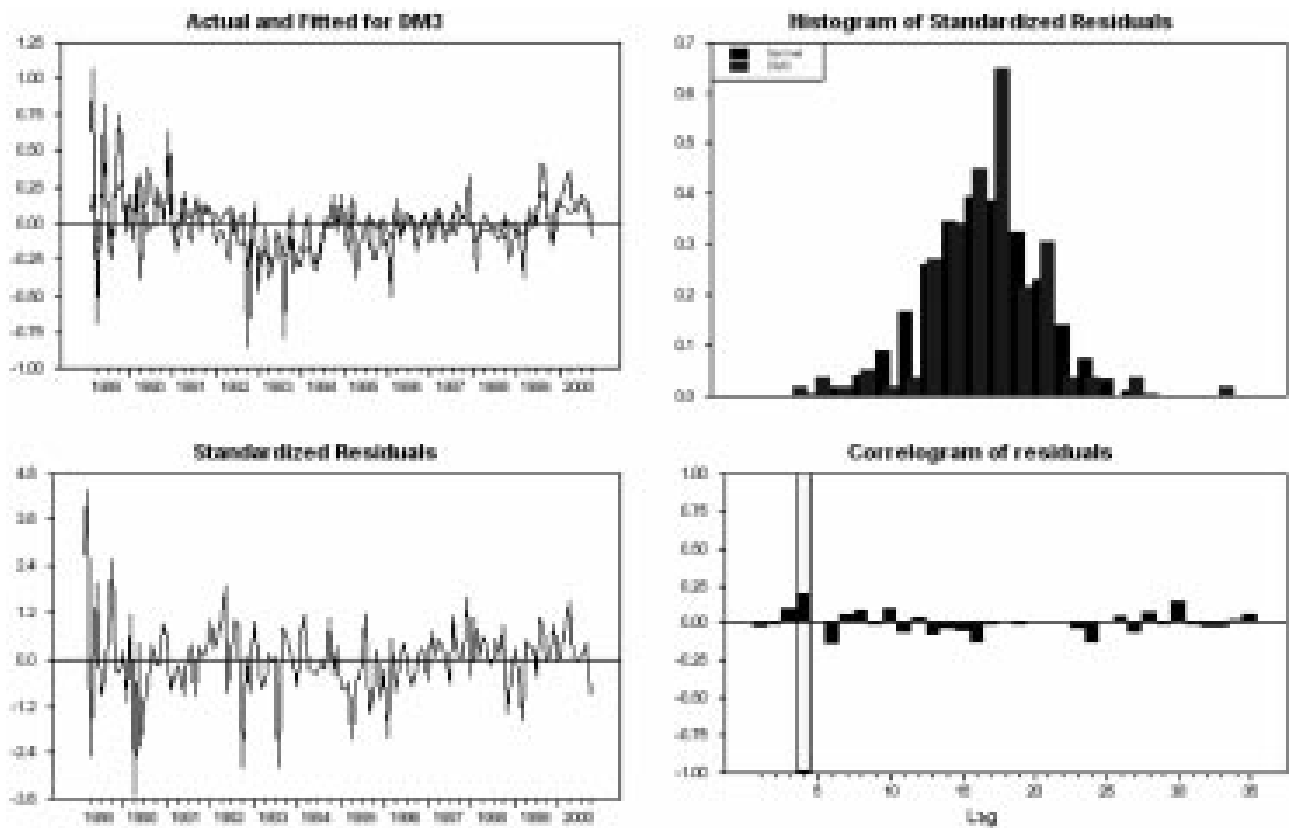

Figure 13. Residual series (ED6 equation).
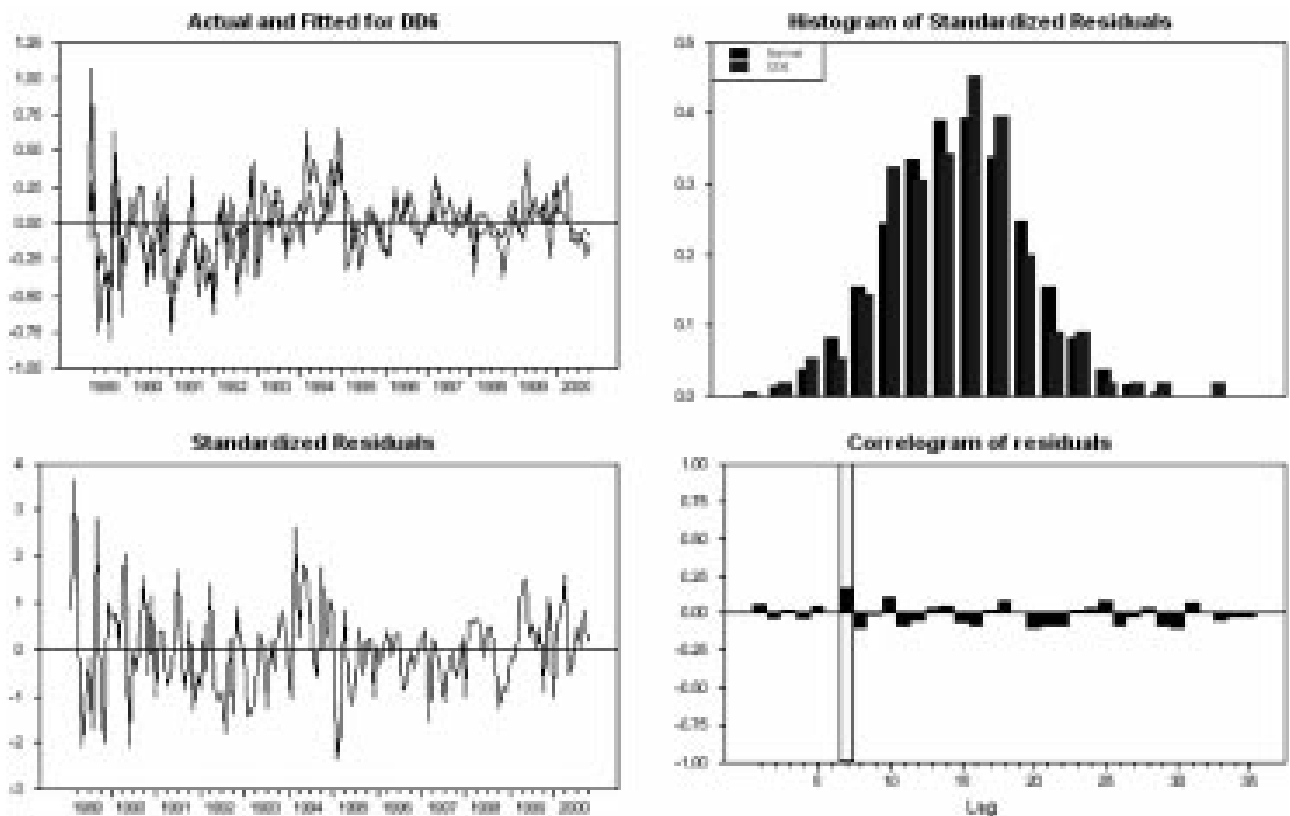
Figure 14. Residual series (ES6 equation).
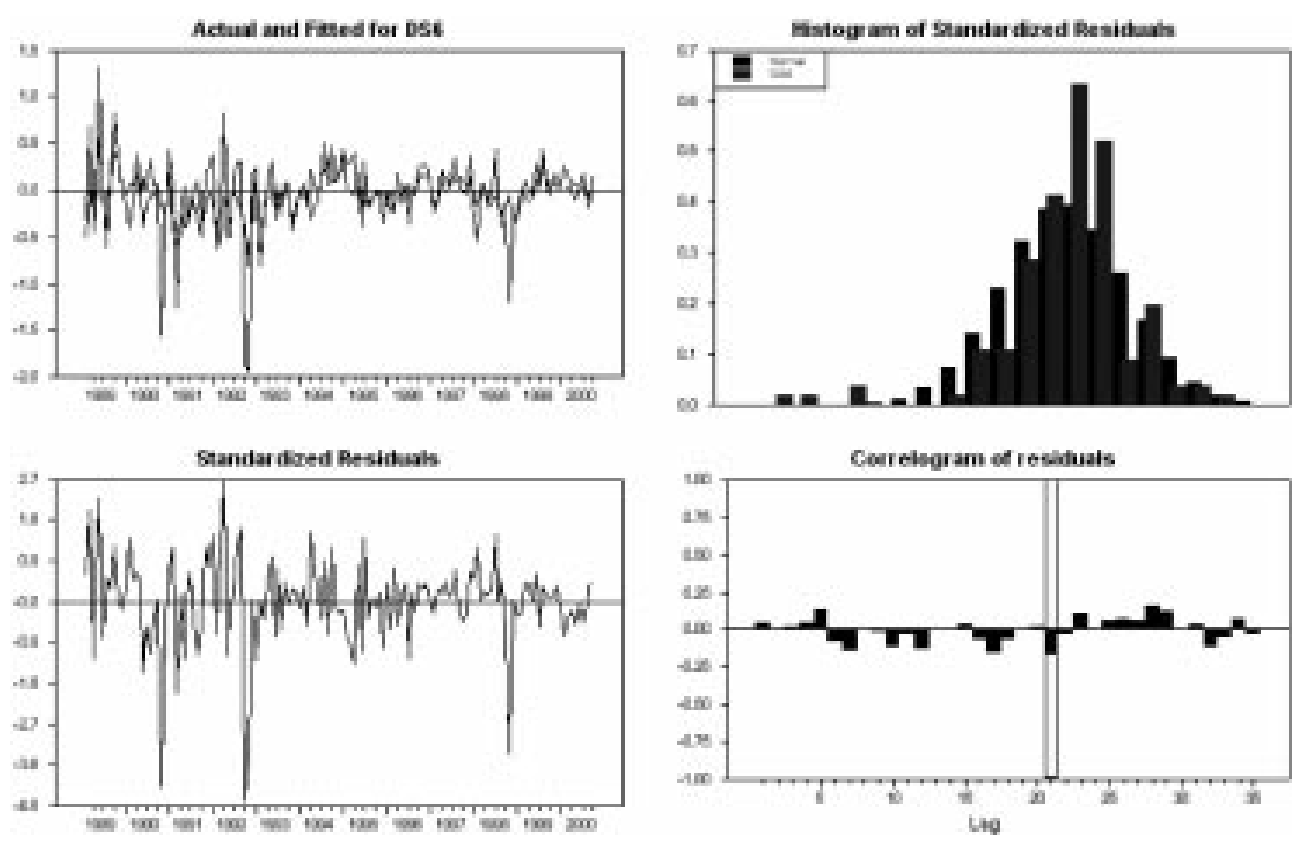

Figure 15. Residual series (EM6 equation).
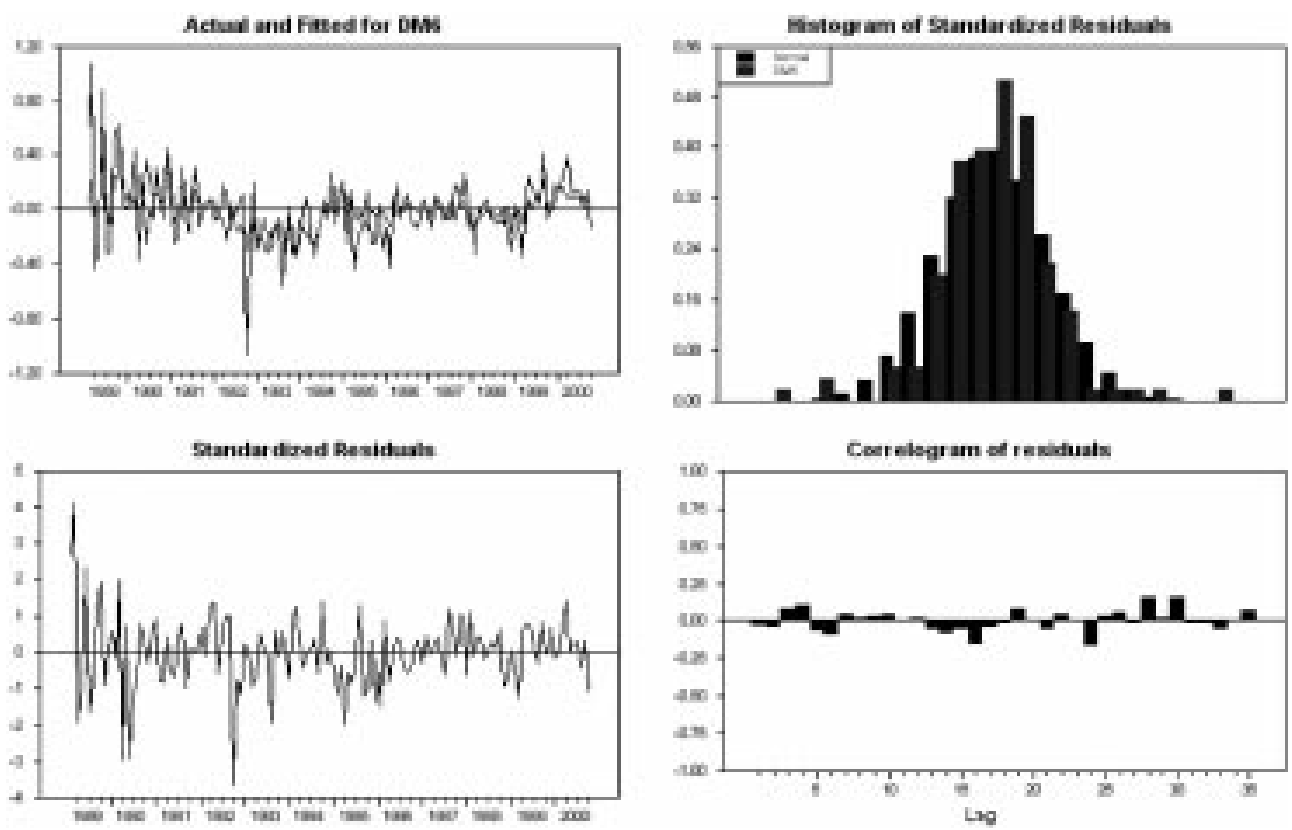
Eurocurrency interest rates exhibit long run interdependence and therefore are integrated to some extent.

\section{B. Principal Components Results}

After having observed and discussed the findings of the Cointegration methodology attention now turns to PCA. It should be noted that the PCA requires stationarity of the series, so the first differences were employed to achieve stationarity. Table 3 reports the results of the PCA.

There are only three significant ${ }^{8}$ principal components explaining among themselves $90.81 \%$ of the system's total variation. The first principal component explain $49.14 \%$ of the total variation, the second $25.35 \%$, and the third $16.3 \%$ (Panel A, Table 3).

The loading factors to the three principal components (Panel B, Table 3) show that all interest rates are highly correlated with a uniform sign (positive) to the first principal component. As far as the second component is concerned, the US rates are highly correlated (positively) with it, whereas the European rates are less sensitive to it (also negatively correlated). Finally, the European rates are more sensitive with respect to the third factor, with the US rates exhibiting very low sensitivity.

In such cases, moving from the description of the results to their interpretation is not a straightforward operation. The basic problem is that the PCA does not explicitly identify the factors. Therefore, claiming what they exactly represent is not strictly valid. However, provided that one bears this caution in mind an attempt can be made to provide some intuitive explanation of the results. Our interpretation is that the first principal component may represent the 'world price of risk' (Harvey, 1991). In other words, rates are mainly driven by world market condiions and thus capturing 'world systemic risk'. If one is prepared to believe in the validity of an international asset-pricing model then such an interpretation would not be too extreme.

Regarding the other two components, our interpretation is that they mainly capture the business cycle in the two economic regions identified in the dataset. In particular, the second component is associated with the US business cycle, whereas the third with the European. Such an interpretation would account for the fact that the US (European) rates are more (less) sensitive to the second factor and

\footnotetext{
${ }^{8}$ The criterion used to assess the significance of a factor was the Kaiser's test, which basically qualifies a factor as significant when the associated eigenvalue is greater than unity.
} 
Table 3. Principal Components Results

\begin{tabular}{|cccc|}
\hline \multicolumn{4}{c|}{ Panel A } \\
\hline Component & Eigenvalues $^{\mathrm{a}}$ & $\begin{array}{c}\text { \% of Variance } \\
\text { Explained }\end{array}$ & Cumulative \% \\
\hline 1 & 4.42 & 49.14 & 49.14 \\
\hline 2 & 2.2 & 25.35 & 75.05 \\
3 & 1.46 & 16.3 & 90.81 \\
\hline \multicolumn{5}{c}{ Panel B } \\
\hline Feries & Factor 1 Loadings \\
\hline ED1 & 0.56 & Factor 2 & Factor 3 \\
ED3 & 0.58 & 0.7 & 0.12 \\
EM1 & 0.54 & 0.77 & 0.22 \\
EM3 & 0.73 & 0.75 & -0.59 \\
EM6 & 0.8 & Sn & -0.54 \\
ES1 & 0.83 & -0.13 & -0.46 \\
ES3 & 0.69 & -0.16 & 0.38 \\
ES6 & 0.76 & -0.48 & 0.42 \\
\hline
\end{tabular}

${ }^{a}$ Only the first three largest (significant) eigenvalues are reported. The criterion used to assess the significance of a factor was the Kaiser's test (Kaiser, 1960), qualifying a factor as significant when the associated eigenvalue is greater than unity.

${ }^{\mathrm{b}} \mathrm{Sn}$ stands for small number.

vice versa for the third factor. Additionally, it would also account for the fact that all rates are correlated (although at a different degree) with both factors. This could be seen via some sort of international transmission of national monetary policies. It is a well-established fact that changes in policy, say by the Federal Open Market Committee (US) typically have repercussions to the decisions of the Bundesbank (Germany) and the Monetary Policy Committee (UK). Additionally, it could be explained in the light of spillovers, which are plausible in 'globalised' markets (Christiansen and Piggot, 1997).

\section{Conclusion}

The goal of the analysis presented was to explore the issue of Eurocurrency market integration. In order to do so, Cointegration and Principal Components Analyses were employed to test the hypothesis that Eurocurrency rates are driven by a common set of factors. In other words, the hypothesis tested was that the interest rates exhibited sensitivity to a common set of factors that characterises 
their multivariate correlation structure.

The empirical findings provide evidence that is consistent with the hypothesis of market integration. Thus, the main conclusion reached was that the Eurocurrency market is indeed integrated since interest rates are exhibiting sensitivity to a common set of factors both in the long and in the short run. Therefore, as far as modelling is concerned, the evidence presented in the paper is that it is appropriate to model Eurocurrency rates in a multivariate framework and also allow for term structure effects (that is, include more that one maturity). Finally, as far as economic policy is concerned, the analysis indicates that interest rates are interrelated across financial centres and as a result policies cannot be designed independently.

The main goal of future research should be to attempt an explicit identification of these factors and directly test a global APT model.

\section{Acknowledgement}

The author is grateful to two anonymous referees for their helpful comments and insights. Discussions with Mr. Roy Bailey have also been beneficial in shaping the ideas presented in the paper.

Date accepted: March 2001

\section{References}

Arshanapalli, B. and Doukas, J. (1994), "Common Stochastic Trends in a System of Eurocurrency Rates", Journal of Banking and Finance, 18, 1047-1061.

Barro, R. and Sala-i-Martin, X. (1990). "World Real Interest Rates", In O. Blanchard and S. Fischer (eds), Macroeconomics Annual, MIT Press.

Blundell-Wignall, A. and Browne, F. (1991). "Increasing Financial Market Integration, Real Exchange Rates and Macroeconomic Adjustment", OECD Department of Economics and Statistics Working Paper, No 67.

Breeden, D. (1979). "An Intertemporal Asset Pricing Model with Stochastic Consumption and Investment Opportunities", Journal of Financial Economics, 7, 265-296.

Bremnes, H., Gjerde, O. and Saetem, F. (1997), “A Multivariate Cointegration Analysis of Interest Rates in the Eurocurrency Market", Journal of International Money and Finance, 16(5), 767-778.

Caramaza, F., K. Clinton, A. Cote and Longworth, D. (1986), "International Capital Mobility and Asset Substitutability: some theory and evidence on recent structural 
changes", Bank of Canada Technical Report, No 44.

Christiansen, H. and Piggot, C. (1997), "Long Term Interest Rates in Globalised Markets", OECD Working Paper, No 175.

Dickey, D. and Fuller, W. (1979), "Distribution of Estimators for Autoregressive Time Series with a Unit Root", Journal of the American Statistical Association, 84, 427-431.

Dickey, D. and Fuller, W., (1981) "Likelihood Ratio Statistics for Autoregressive Time Series with a Unit Root", Econometrica, 49, 1057-1072.

Fase, M. and Vlaar, P. (1998), "International Convergence of Capital Market Interest Rates”, De Economist, 146, 2, 257-269.

Fase, M. (1973), "A Principal Components Analysis of Market Interest Rates in the Netherlands, 1962-1970”, European Economic Review, 4, 107-134.

Fase, M. (1976), "The Interdependence of Short-Term Interest Rates in the Major Financial Centres of the World: Some Evidence for 1961-1972”, Kyklos, 29, 63-96.

Frankel, J. (1992), "Measuring World Capital Mobility: A Review”, American Economic Review, 88, 197-202.

Goldstein, M. and Mussa, M. (1993), “The Integration of World Capital Markets", In Changing Capital Markets, proceedings of the symposium sponsored by the Federal Bank of Kansas City.

Goodwin, B. and Grennes, T. (1994), "Real Interest Rate Equalization and the Integration of International Financial Markets”, Journal of International Money and Finance, 13, 107-124.

Gruijters, D. (1995), "Financiele Integratie en monetair Beleid: Een empirisch Onderzoek naar de Mobiliteit vaan het Kapitaalrkeer in de geindustrailiseerde Wereld sinds het Einde van het Bretton-Woods-stelsel", No 78 in Publication Series, Amsterdam, NIBE.

Hansen, H. and Juselius, K. (1995), "Cointegration Analysis of Time Series”, CATS in RATS Manual, Estima, Evanston.

Harman, H. (1968), "Modern Factor Analysis", Chicago: University of Chicago Press. Harvey, C. (1991), "The World Price of Covariance Risk", Journal of Finance, 46, 1, 111 157.

Hotelling, H. (1933), "Analysis of Complex and Statistical Variables into Principal Components", Journal of Educational Psychology, 24, 417-441, 498-520.

Johansen, S. (1988), "Statistical Analysis of Cointegration Vectors", Journal of Economic Dynamics and Control, 12(2), 231-254.

Johansen, S. (1991), "Estimation and Hypothesis Testing of Cointegration Vectors in Gaussian Vector Autoregressive Models", Econometrica, 59, 1551-1580.

Johansen, S. (1995), Likelihood-Based Inference in Cointegrated Vector Autoregressive Models, Oxford University Press, Oxford.

Johansen, S. and Juselius, K. (1990), "Maximum Likelihood Estimation and Inference on Cointegration-With Application to the Demand for Money", Oxford Bulletin of Economics and Statistics, 52, 169-210.

Kaiser, H. (1960), "The application of electronic computers to factor analysis", 
Educational and Psychological Measurement, 20, 141-151.

Knez, P., Litterman, R. and Scheinkman, J. (1994), "Explorations into Factors Explaining Money Market Returns", Journal of Finance, XLIX (5), 1861-1882.

Lawley, D. and Maxwell, A. (1971), "Factor Analysis as a Statistical Method”, (2 ${ }^{\text {nd }}$ ed.), London: Butterworths.

Mundell, R. (1968), “International Economics”, New York: Macmillan.

Litterman, R. and Scheinkman, J. (1989), "Common Factors Affecting Bond Returns", Journal of Fixed Income, 1, 54-61.

Osterwald-Lenum, M. (1992), A Note with Quantiles of the Asymptotic Distribution of the Maximum Likelihood Cointegration Rank Test Statistics", Oxford Bulletin of Economics and Statistics, 54, 461-472.

Phillips, P.C.B. and Perron, P. (1988), "Testing for a Unit Root in Time Series Regression", Biometrika, 75, 335-346.

Ross, S. (1976), "The Arbitrage Theory of Capital Asset Pricing”, Journal of Economic Theory, 13, 341-360.

Schwarz, G. (1978), "Estimating the Dimension of a Model”, Annals of Statistics, 2, 461464.

Sharpe, W. (1964), "Capital Asset Prices: A Theory of Market Equilibrium under conditions of Risk", Journal of Finance, 19, 425-442.

Solnik, B. (1974), “An Equilibrium Model for the International Capital Market”, Journal of Economic Theory, 8, 500-524.

Sutton, G. (1996), "Comovements of Canadian, UK, and US bond yields", in Financial Market Volatility: Measurement, Causes and Consequences, BIS Conference papers, vol. 1.

Tesar, L. and Warner, I. (1992), "Home Bias and the Globalisation of Securities Markets", NBER Working Paper, No 4218. 